\title{
Is there a need to control the placebo in placebo controlled trials?
}

The standard method of evaluating drugs is the randomised, placebo controlled, clinical trial. ${ }^{1}$ In a letter to Nature, Golomb remarked that "It is paradoxical that there is no standard of evidence to support the standard of evidence". ${ }^{2}$ She referred to the fact that the US Food and Drug Administration and other regulatory agencies have no regulations for the constituents of placebos used in clinical trials. ${ }^{3}$ In reports of clinical trials the composition of the placebo medication is usually not described. Golomb noted some exceptions to this practice. In several early studies that explored the use of cholesterol lowering agents in heart disease the placebo medication was stated: capsules with olive oil in one case ${ }^{4}$ and corn oil in another. ${ }^{5}$ It is now widely accepted that these oils can reduce low density lipoprotein, ${ }^{6}$ a factor known to be associated with coronary heart disease. To what extent does the use of possibly non-inert placebos threaten the validity of randomised, placebo controlled, clinical trials?

\section{Placebos and large scale randomised clinical trials} The use of placebos in clinical trials helps to mask the treatment allocation: patients do not know whether they are taking active medication or placebo and the physician does not know to which treatment the patient has been allocated. Hence, use of a placebo eliminates the subjective effects of the pill-taking ritual and the effects of intended and unintended behavioural changes.

Masking the physician to the treatment allocation guarantees that, on average, patients in both groups will receive identical medical care. Masking the treatment allocation will be achieved only if the placebo medication is the same size, colour, and shape as the active drug and tastes the same. ${ }^{7}$ Furthermore, outcome assessment in both groups will be unbiased and this will improve the internal validity of the comparison between the placebo and active medication groups. ${ }^{8}$

A few decades ago relatively small trials were conducted because large treatment effects were expected-for example, in the assessment of the effect of clofibrate, a cholesterol lowering drug. The four largest trials included a variable number of patients, from 497 to $15745 .^{59-11}$ The medical importance of small treatment effects implies the need for large-scale randomised trials. ${ }^{12}$ For example, mega-trials have become the standard of evidence in the treatment of patients with definite or suspected acute myocardial infarction. If the placebo has a large deviation from inertness it is obvious that the results of any trial will be biased, but even low placebo activity could bias the comparison when the absolute treatment effect is small. In this setting a positive, negative, or null effect of a drug might be the consequence of a negative, positive, or samedirection effect of the placebo.

\section{Hypothetical examples of the consequences of a beneficial placebo}

To illustrate these effects we generated five hypothetical trials. All trials evaluated the same medication against the same placebo. Drug administration, duration of follow up, and outcome assessment was identical in all trials. For all trials the main outcome event was mortality. The relative benefit of the medication was constant and mortality in the control group declined. Suppose that in these trials the placebo medication was not truly inert but had prevented one death per 1000 patients treated with the placebo. The working mechanism by which the placebo had prevented the deaths was independent of the disease under study, so a constant percentage of the total number of patients in the control group was affected by it. This means that an extra $0.1 \%$ of deaths would have occurred in the patients treated with placebo if a truly inert placebo had been used. The relative bias in the risk difference attributable to the beneficial placebo increased from $1 \%$ in the trial with the largest risk difference to $10 \%$ in the trial with the smallest risk difference (table 1 )

In the previous example the placebo was assumed to prevent a constant percentage of deaths in the control group because the deviation from inertness was assumed to be independent of the disease under study. Suppose that, like the olive oil and corn oil in the clofibrate trials, the deviation from inertness is related to the disease under study. Now the mortality prevented by the beneficial placebo will not be a constant percentage of the total number of patients in the control group, but a constant percentage of the total number of deaths in the control group. Suppose that in the five hypothetical trials, two per cent of the total number of the deaths in the control were

Table 1 Five hypothetical trials demonstrating the relative bias in the absolute risk difference due to a beneficial placebo

\begin{tabular}{|c|c|c|c|c|c|c|c|}
\hline \multicolumn{2}{|c|}{ Mortality rate (\%) } & \multirow[b]{2}{*}{$R R$} & \multirow[b]{2}{*}{$\begin{array}{l}R D \\
(\%)\end{array}$} & \multirow[b]{2}{*}{$\begin{array}{l}\text { Independent beneficial } \\
\text { effect of placebo (\%) }\end{array}$} & \multirow{2}{*}{$\begin{array}{l}\text { Relative bias } \\
\text { in } R D \text { due to } \\
\text { an independent } \\
\text { beneficial } \\
\text { placebo (\%)t }\end{array}$} & \multirow{2}{*}{$\begin{array}{l}\text { Dependent } \\
\text { beneficial } \\
\text { effect of } \\
\text { placebo (\%)* }\end{array}$} & \multirow{2}{*}{$\begin{array}{l}\text { Relative bias } \\
\text { in } R D \text { due to } \\
\text { a dependent } \\
\text { beneficial placebo (\%) }\end{array}$} \\
\hline $\begin{array}{l}\text { Active } \\
\text { medication }\end{array}$ & Control & & & & & & \\
\hline $\begin{array}{r}40 \\
20 \\
12 \\
8 \\
4\end{array}$ & $\begin{array}{r}50 \\
25 \\
15 \\
10 \\
5\end{array}$ & $\begin{array}{l}0 \cdot 8 \\
0 \cdot 8 \\
0 \cdot 8 \\
0 \cdot 8 \\
0 \cdot 8\end{array}$ & $\begin{array}{r}10 \\
5 \\
3 \\
2 \\
1\end{array}$ & $\begin{array}{l}0 \cdot 1 \\
0 \cdot 1 \\
0 \cdot 1 \\
0 \cdot 1 \\
0 \cdot 1\end{array}$ & $\begin{array}{r}1 \\
2 \\
3 \\
5 \\
10\end{array}$ & $\begin{array}{l}1 \cdot 0 \\
0 \cdot 5 \\
0 \cdot 3 \\
0 \cdot 2 \\
0 \cdot 1\end{array}$ & $\begin{array}{l}10 \\
10 \\
10 \\
10 \\
10\end{array}$ \\
\hline
\end{tabular}

$R R$, risk ratio; $R D$, risk difference.

^Independent beneficial effect indicates that the working mechanism by which the placebo prevents deaths is unrelated to the disease under study. Dependent beneficial effect indicates that the working mechanism by which the placebo prevents deaths is related to the disease under study.

tRelative bias in risk difference $=$ (beneficial effect of placebo:risk difference) $\times 100 \%$. 
Table 2 Five randomised clinical trials of effective drugs in the treatment of acute myocardial infarction demonstrating the relative bias in the absolute risk difference due to a hypothetical independent beneficial placebo

\begin{tabular}{|c|c|c|c|c|c|c|}
\hline \multirow[b]{2}{*}{ Study } & \multicolumn{2}{|c|}{ Mortality within observation period } & \multirow[b]{2}{*}{$R R$} & \multirow[b]{2}{*}{$R D(\%)$} & \multirow{2}{*}{$\begin{array}{l}\text { Hypothetical } \\
\text { independent beneficial } \\
\text { effect of placebo (\%) }\end{array}$} & \multirow{2}{*}{$\begin{array}{l}\text { Relative bias in } R D \text { due to a } \\
\text { hypothetical independent } \\
\text { beneficial placebo (\%) }\end{array}$} \\
\hline & Active medication & Control & & & & \\
\hline Gormsen et al ${ }^{13}$ & $\begin{array}{l}2 / 14 \\
(14 \cdot 3 \%)\end{array}$ & $\begin{array}{l}3 / 14 \\
(21 \cdot 4 \%)\end{array}$ & $0 \cdot 67$ & $7 \cdot 1$ & $0 \cdot 1$ & $1 \cdot 4$ \\
\hline Australian trial ${ }^{14}$ & $\begin{array}{l}51 / 376 \\
(13.6 \%)\end{array}$ & $\begin{array}{l}63 / 371 \\
(17 \cdot 0 \%)\end{array}$ & $0 \cdot 80$ & $3 \cdot 4$ & $0 \cdot 1$ & $2 \cdot 9$ \\
\hline BHAT $^{15}$ & $\begin{array}{l}138 / 1916 \\
(7 \cdot 2 \%)\end{array}$ & $\begin{array}{l}188 / 1921 \\
(9.8 \%)\end{array}$ & $0 \cdot 73$ & $2 \cdot 6$ & $0 \cdot 1$ & $3 \cdot 8$ \\
\hline ISIS-2 ${ }^{16}$ & $\begin{array}{l}791 / 8592 \\
(9 \cdot 2 \%)\end{array}$ & $\begin{array}{l}1029 / 8595 \\
(12 \cdot 0 \%)\end{array}$ & $0 \cdot 77$ & $2 \cdot 8$ & $0 \cdot 1$ & $3 \cdot 6$ \\
\hline ISIS-4 ${ }^{17}$ & $\begin{array}{l}2088 / 29028 \\
(7 \cdot 2 \%)\end{array}$ & $\begin{array}{l}2231 / 29022 \\
(7 \cdot 7 \%)\end{array}$ & 0.94 & 0.5 & $0 \cdot 1$ & 20 \\
\hline
\end{tabular}

$R R$, risk ratio; $R D$, risk difference.

See the legend of table 1 for explanation of independent beneficial effect and for the formula to calculate the relative bias.

prevented by the beneficial placebo. In this case the relative bias in the risk difference due to the beneficial placebo remains constant (table 1).

To further illustrate these effects we chose five real clinical trials assessing the effect on mortality of different drugs in the treatment of acute myocardial infarction. ${ }^{13-17}$ All studies used different inclusion and exclusion criteria, different follow up periods, and different control medication. The relative treatment effect of the various drugs ranged from 0.67 to 0.94 . Over the years smaller risk differences were found, partially because of the decreasing relative treatment effect and partially because of decreasing mortality in the control group. Suppose that in these trials the placebo medication was not truly inert but had affected $0.1 \%$ of the patients in the control group. The relative bias in the risk difference caused by the beneficial placebo would then increase from $1.4 \%$ in the trial with the largest risk difference to $20 \%$ in the trial with the smallest risk difference (table 2). We realise that the duration of exposure to the non-inert placebo and the duration of follow up will be important determinants of the influence of the non-inert placebo, but we will not discuss these factors here. Moreover, we are not saying that the results obtained in these trials were biased by a beneficial effect of the placebo. This is merely a numerical example of what could happen in the assessment of small treatment effects with control medication that is not completely inactive.

In conclusion, the relative bias in the risk difference caused by a non-inert placebo increases with smaller absolute treatment effects only if the deviation from inertness is independent of the disease under study. We think that the possible non-inertness of a placebo will be independent of the disease under study in most instances, but there are certainly exceptions. A comparison can be made with the model that suggests separating benefit and harm of health care interventions, initially proposed by Lubsen and Tijssen ${ }^{18}$ and further developed by Hoes et al ${ }^{19}$ and Glasziou and Irwig. ${ }^{20}$ They suggested that intended patient benefit increases with risk of disease but that rates of adverse events are independent of risk of disease.

\section{Implications for research}

Many factors can influence the internal validity of a trial. These include a flawed randomisation procedure, better co-medication in the control group, and poor placebos. The internal validity of large clinical trials in which small effects are anticipated is more vulnerable to such small deviations than are smaller trials in which large effects are anticipated. Furthermore, as we have shown ${ }^{21}$ it may be important to give full descriptions of the circumstances and setting in which the trials take place because placebo effects and variables in the setting may interact with the drug under study.
Do we need to control the placebo in placebo controlled clinical trials? Our examples show that small effects of placebos can affect the internal validity and hence the results of trials assessing small absolute treatment effects. So there is certainly a need for further study of placeborelated effects in clinical trials as they become increasingly important. However, it is not possible to test the placebo for true inertness. What placebo should it be tested against? A placebo can only be assumed to be inert according to current knowledge.

Twenty five years ago who would have thought that the olive oil and corn oil used as placebo medication in the clofibrate trials was not truly inert? Because it is impossible to test the placebo for inertness, in future trials the constituents of the placebos should be described because they might later prove not to be inert.

ANTON JM DE CRAEN JAN GP TIJSSEN

Academic Medical Centre, University of Amsterdam, Department of Clinical Epidemiology E Biostatistics, PO Box 22700, 1100 DE Amsterdam

1 Dollery CT. A bleak outlook for placebos (and for science). Eur $\mathcal{f}$ Clin Pharmacol 1979;15:219-21.

2 Golomb BA. Paradox of placebo effect. Nature 1995;375:530.

3 Collier J. Confusion over use of placebos in clinical trials. Better guidelines needed. $B M \mathcal{F}$ 1995;311:821-2.

4 Acheson J, Hutchinson EC. Controlled trial of clofibrate in cerebral vascular disease. Atherosclerosis 1972;15:177-83.

5 Research Committee of the Scottish Society of Physicians. Ischaemic heart disease: a secondary prevention trial using clofibrate. $B M \mathcal{F} 1971$;iv: 775-84.

6 Grundy SM, Denke MA. Dietary influences on serum lipids and lipoproteins. F Lipid Res 1990;31:1149-72.

7 Joyce CRB. Placebos and other comparative treatments. $\mathrm{Br} f \mathrm{Clin}$ Pharmacol 1982;13:313-8.

8 Schulz KF, Chalmers I, Haynes RJ, Altman DG. Empirical evidence of bias. Dimensions of methodological quality associated with estimates of bias. Dimensions of methodological quality associated with es

9 Group of Physicians of the Newcastle upon Tyne Region. Trial of clofibrate in the treatment of ischaemic heart disease. Five year study. $B M \mathcal{J}$ brate in the trea
$1971 ;$ iv:767-75.

10 Coronary Drug Project Research Group. Clofibrate and niacine in coronary heart disease. $\mathcal{F A M A} 1975 ; 231: 360-81$.

11 Committee of Principal Investigation. A co-operative trial in the primary prevention of ischaemic heart disease using clofibrate. Br Heart $尹 1978$; 40:1069-118.

12 Peto R, Collins R, Gray R. Large-scale randomized evidence: large simple rials and overviews of trials. F Clin Epidemiol 1995;48:23-40.

13 Gormsen J, Tidstrom B, Feddersen C, Ploug J. Biochemical evaluation of low dose urokinase in acute myocardial infarction. A double blind study. Acta Med Scand 1973;194:191-8.

14 Australian multicentre trial of streptokinase in acute myocardial infarction Med f Aust 1977;1:553.

$15 \beta$-Blocker Heart Attack Trial Research Group (BHAT). A randomized tria of propranolol in patients with acute myocardial infarction. $\mathscr{f} A M A$ 1982;247:1707-14.

16 ISIS-2 (Second International Study of Infarct Survival) Collaborative Group. Randomised trial of intravenous streptokinase, oral aspirin, both or neither among 17187 cases of suspected acute myocardial infarction ISIS-2. Lancet 1988;ii:349-60.

17 ISIS-4 (Fourth International Study of Infarct Survival) Collaborative Group. ISIS-4: A randomised factorial trial assessing early oral captopril oral mononitrate, and intravenous magnesium sulphate in 58050 patients with suspected acute myocardial infarction. Lancet 1995;345: 669-85.

18 Lubsen J, Tijssen JGP. Large trials with simple protocols: indications and contraindications. Control Clin Trials 1989;10:151S-60S.

19 Hoes AW, Grobbee DE, Lubsen J. Does drug treatment improve survival Reconciling the trials in mild-to-moderate hypertension. I Hyperten 1995;13:805-11.

20 Glasziou PP, Irwig LM. An evidence based approach to individualising treatment. $B M \mathcal{F}$ 1995;311:1356-9.

21 Kleijnen J, de Craen AJM, van Everdingen J, Krol L. Placebo effect in double-blind clinical trials: a review of interactions with medications. Lancet 1994;344:1347-9. 